\title{
Research funding for pain in Canada
}

\author{
Mary E Lynch MD FRCP ${ }^{1}$, Donald Schopflocher PhD², Paul Taenzer PhD ${ }^{3}$, Caitlin Sinclair BSc ${ }^{1}$
}

ME Lynch, D Schopflocher, P Taenzer, C Sinclair. Research funding for pain in Canada. Pain Res Manage 2009;14(2):113-115.

\begin{abstract}
Chronic pain is an escalating public health problem. There are inadequate resources to assist patients suffering with pain in Canada. Therefore, it is important that research examining novel and appropriate treatment for chronic pain is conducted. To determine the current level of research funding for pain in Canada, the Canadian Pain Society conducted a survey. Of 79 active researchers performing pain-related studies, 65 received funding in the past five years amounting to a total of approximately $\$ 80.9$ million. This is less than $1 \%$ of the total funding from the Canadian Institutes of Health Research and $0.25 \%$ of the total funding for health research.
\end{abstract}

Key Words: Chronic pain; Economic burden; Research funding

$\mathrm{C}$ hronic pain is associated with significant direct health care costs (1). Using direct costs reported for Alberta (2) and Canadian population figures, the direct health care costs for Canada were estimated to be $\$ 6.02$ billion per year (in year 2000 dollars) for individuals suffering from chronic pain. Of this total, $\$ 4.25$ billion are excess costs beyond those expected for Canadians without chronic pain. By 2025, with the aging of the population, these costs can be expected to rise to $\$ 10.29$ billion per year, of which $\$ 7.26$ billion will be excess costs. These estimates do not include significant societal costs related to disability and lost productivity. There is a critical need to address the needs of this population, but the challenges are significant.

The Canadian Medical Association and other members of the Wait Time Alliance have identified national benchmarks for the management of pain, with maximum waits of six months for adults with chronic pain and shorter benchmarks for specific types of pain that are potentially reversible if treated early (3). A national survey has demonstrated that wait times for treatment at publicly funded pain clinics across Canada exceed these benchmarks, with wait times of longer than one year at over $30 \%$ of clinics, ranging up to five years, with large areas of Canada having no service (4). Furthermore, it has been shown that people who suffer from chronic pain deteriorate while waiting for access to care. This deterioration includes increased pain and decreased health-related quality of life, as well as escalated depression (5).

To address the health care needs of Canadians in the future, research funding examining novel and appropriate treatment for chronic pain in the present is critical. A recent study (6) has demonstrated that reductions in funding for pain research

\section{Financement de la recherche sur la douleur au Canada}

La douleur chronique est un problème de santé publique qui va croissant. Au Canada, nous disposons de ressources insuffisantes pour aider les patients qui souffrent à composer avec la douleur. C'est pourquoi il est important d'approfondir la recherche sur de nouveaux traitements appropriés pour la douleur chronique. Afin de déterminer le niveau actuel de financement de la recherche sur la douleur au Canada, la Société canadienne de la douleur a procédé à un sondage. Sur 79 chercheurs travaillant activement à des projets reliés à la douleur, 65 ont reçu du financement au cours des cinq dernières années, totalisant environ 80,9 millions de dollars. Cela représente moins de $1 \%$ du financement total accordé par les Instituts de recherche en santé du Canada et 0,25\% du financement total de la recherche en santé.

have exceeded reductions in total National Institutes of Health (NIH) funding in the United States. The Canadian Pain Society (CPS) has been concerned that there may be inadequate funding for pain research in Canada. To examine this further, a national survey of investigators performing pain research in Canada was conducted.

\section{METHODS}

A 'snowball' strategy was used to distribute a one-page survey (Figure 1) to all members of the CPS by e-mail. Respondents were requested to forward the survey to additional researchers who may not have been members of the CPS. The final list of respondents was reviewed by five leading Canadian pain researchers and the CPS executive committee to assure that all known investigators were included. For those who did not respond initially, further requests were made by e-mail and telephone until responses were obtained from all.

\section{RESULTS}

In total, 79 responses were received. Of these, 65 had received funding for pain research in the past five years. The total amount of funding over the past five years was approximately $\$ 80.9$ million, of which approximately $\$ 42.7$ million came from the Canadian Institutes of Health Research (CIHR). The next largest source of funding was categorized as 'other' and included funding from the Canada Foundation for Innovation and the NIH in the United States, among others. Provincial funding was the third largest source, amounting to approximately $\$ 7.5$ million. The sources of research funding are presented in Table 1. The distribution of research dollars by province is shown in Figure 2. 


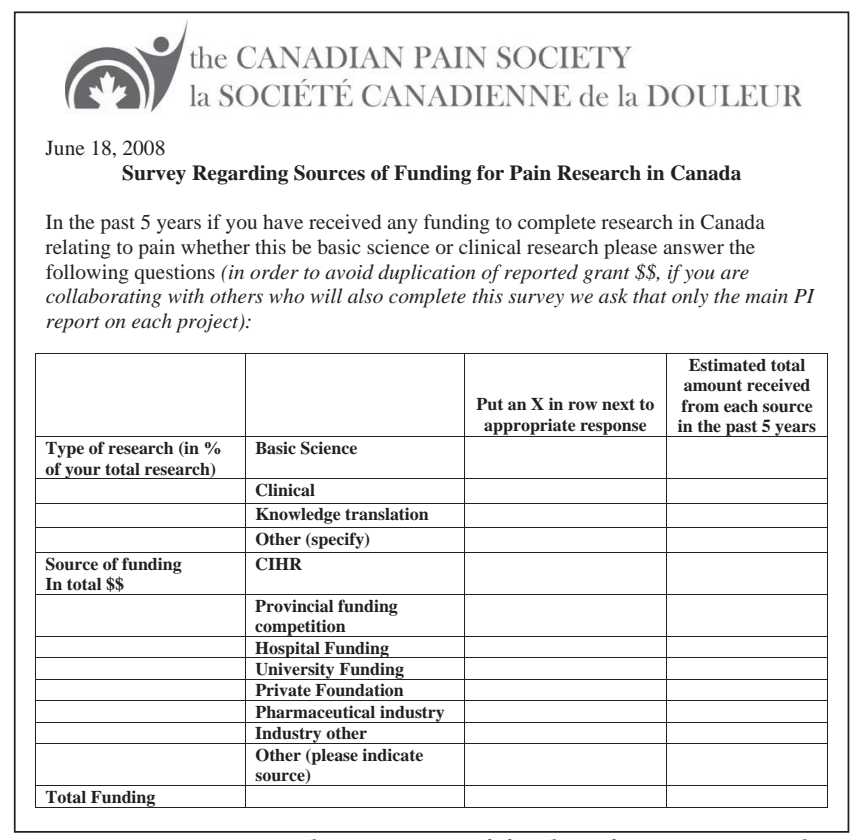

Figure 1) Survey regarding sources of funding for pain research in Canada. CIHR Canadian Institutes of Health Research; PI Principal investigator

\section{TABLE 1}

\section{Sources of pain research funding in Canada from 2003} to 2008

\begin{tabular}{lrr}
\hline Source & \% & \multicolumn{1}{c}{ Total, \$ } \\
\hline Canadian Institutes of Health Research & 53 & $42,743,758$ \\
Provincial & 9 & $7,508,631$ \\
Hospital & 1 & 946,425 \\
University & 2 & $1,357,540$ \\
Private & 4 & $3,233,054$ \\
Pharmaceutical & 5 & $3,956,856$ \\
Industry & 1 & 652,500 \\
Other & 25 & $20,533,210$ \\
Total & & $80,931,974$ \\
\hline
\end{tabular}

\section{DISCUSSION}

According to figures obtained from personal communications with the CIHR, the total CIHR funding for research in the past five years was $\$ 3.8$ billion. Thus, approximately $1.1 \%$ of CIHR funding has gone to pain research in the past five years. Furthermore, only six randomized controlled trials examining treatments for pain have been funded since 1999, and only two of these involved chronic pain. Statistics Canada (7) reported that total spending on research and development in the health field amounted to $\$ 6.3$ billion for 2007 , with $\$ 29.6$ billion spent in the five-year period from 2003 through 2007. Thus, only approximately $0.25 \%$ of health research funding goes to pain research.

These figures are similar to those in the United States (3), where it was found that only $0.6 \%$ of NIH funding went to pain research in 2007, and that proportional reductions in funding for pain research have exceeded reductions in total NIH funding.

These authors also assert that the meagre $0.6 \%$ investment in pain research at NIH seems seriously out of scale with the impact of pain on the nation's health care burden. They cite a

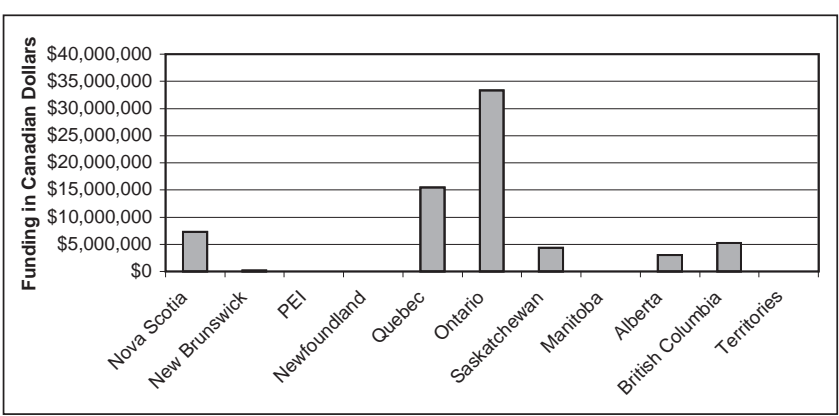

Figure 2) Distribution of pain research funding by province from 2003 to 2008. PEI Prince Edward Island

recent review by Max and Stewart (8) demonstrating that pain accounts for over $20 \%$ of all doctor visits and $10 \%$ of drug sales, and costs developed countries $\$ 1$ trillion each year. In her editorial on the subject, Green (9) refers to the "perfect storm that is brewing", and states that while pain "has reached epidemic proportions, it is a silent epidemic with few NIH dollars devoted to primary research".

Considering the overall burden of pain in Canada, pain research is underfunded. A rough comparison between cancer and chronic pain is instructive. According to the latest available estimates (10), the cost of direct health care for cancer was approximately $\$ 2.5$ billion per year in 1998 . The total amount of research funding for cancer in 2008 was $\$ 390$ million (11). Using these figures, the proportion of research dollars to direct health care costs is approximately 41 times higher for cancer than for chronic pain. Even allowing for increases in the amount of direct health care resources expended on cancer, and allowing for a difference in valuing mortality in cancer and pain, it is clear that pain research is comparatively very underfunded.

Although our focus has been on chronic pain, there is significant evidence that all pain, both acute and chronic, remains inadequately recognized and treated $(12,13)$. It has been demonstrated that acute postoperative pain at moderate to severe levels is experienced by at least one-third of patients, in spite of the availability of good analgesic agents (14). Additional research has found that acute postoperative pain is followed by persistent pain in $10 \%$ to $50 \%$ of individuals after common operations, such as groin hernia repair, breast and thoracic surgery, and coronary artery bypass surgery, and that this chronic pain can be severe in $2 \%$ to $10 \%$, making persistent postsurgical pain a major, largely unrecognized problem (15).

With the aging of our population and our tendency to use more invasive procedures that have been demonstrated to result in increased prevalence of chronic pain (15), the burden of pain will continue to escalate. It is critical that we take steps to address this problem. In a recent topical review, Henry (16) recommended that systemwide strategic action should include a balanced portfolio of curiosity- and needs-based research which, along with existing knowledge, can be mobilized and applied for the benefit of Canadians living with chronic pain. Green (9) stated that the establishment of an interdisciplinary pain research agenda is imperative to improve the state of science and to inform clinical care, particularly for vulnerable and underserved populations, and acknowledged that this will require collaboration among scientific, public health and clinical communities. 
We agree with Henry (16) and Green (9). It is only through the development of a national strategy of pain research that we will be able to address the growing epidemic of chronic pain. If we do not, as stated by Green, "our society will continue to pay an increasingly higher toll for pain complaints while failing to seize the opportunity to reduce its burden”.

\section{REFERENCES}

1. Phillips CJ, Schopflocher D. The economics of pain. In: Taenzer P, Rashiq S, Schopflocher D. Health Policy Perspectives on Chronic Pain. Weinheim: Wiley-Blackwell, 2008:41-50.

2. Schopflocher DP. Chronic Pain in Alberta: A Portrait from the 1996 National Population Health Survey and the 2001 Canadian Community Health Survey. Edmonton: Alberta Health and Wellness, 2003.

3. Wait Time Alliance. Wait Time Alliance Report, Fall 2007. Time for progress: New benchmarks for achieving meaningful reductions in wait times. <http://www.waittimealliance.ca/images/Fall_2007/ time_for_progress.pdf $>$ (Version current at March 24, 2008).

4. Peng P, Choiniere M, Dion D, et al; STOPPAIN Investigators Group. Challenges in accessing multidisciplinary pain treatment facilities in Canada. Can J Anesth 2007;54:977-84.

5. Lynch ME, Campbell F, Clark AJ, et al. A systematic review of the effect of waiting for treatment for chronic pain. Pain 2008;136:97-116.

6. Bradshaw DH, Empy C, Davis P, Lipschitz D, Nakamura Y, Chapman CR. Trends in funding for research on pain: A report on the National Institutes of Health grant awards over the years 2003 to 2007. J Pain 2008;9:1077-87.

7. Statistics Canada. Science Statistics: Estimates of Total Spending on Research and Development in the Health Field in Canada, 1996 to 2007. <http://dsp-psd.pwgsc.gc.ca/collection_2008/statcan/88001-X/88-001-XIE2008003.pdf> (Version current at March 24, 2008).

8. Max MB, Stewart WF. The molecular epidemiology of pain: A new discipline for drug discovery. Nat Rev Drug Discov 2008;7:647-58.

9. Green CR. The healthcare bubble through the lens of pain research, practice, and policy: Advice for the new President and Congress. J Pain 2008;9:1071-3.

10. Public Health Agency of Canada. Economic Burden of Illness in Canada, 1998. <http://www.phac-aspc.gc.ca/publicat/ebic-femc98/ index-eng.php $>$ (Version current at April 7, 2009).

11. Canadian Cancer Research Alliance. Cancer Research Investment in Canada, 2006. <http://www.ccra-acrc.ca/PDF\%20Files/ CCRA_08_EN_Full\%20Report.pdf> (Version current at April 7, 2009).

12. Melzack R. The tragedy of needless pain. Sci Am 1990;262:27-33.

13. Seers K, Watt-Watson J, Bucknall T. Challenges of pain management for the 21st century. J Adv Nurs 2006;55:4-6.

14. Dolin SJ, Cashman JN, Bland JM. Effectiveness of acute postoperative pain management: I. Evidence from published data. Br J Anesth 2002;89:409-23.

15. Kehlet H, Jensen TS, Woolf CJ. Persistent postsurgical pain: Risk factors and prevention. Lancet 2006;367:1618-25.

16. Henry JL. The need for knowledge translation in chronic pain. Pain Res Manage 2008;13:465-76. 


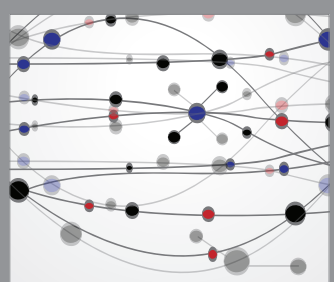

The Scientific World Journal
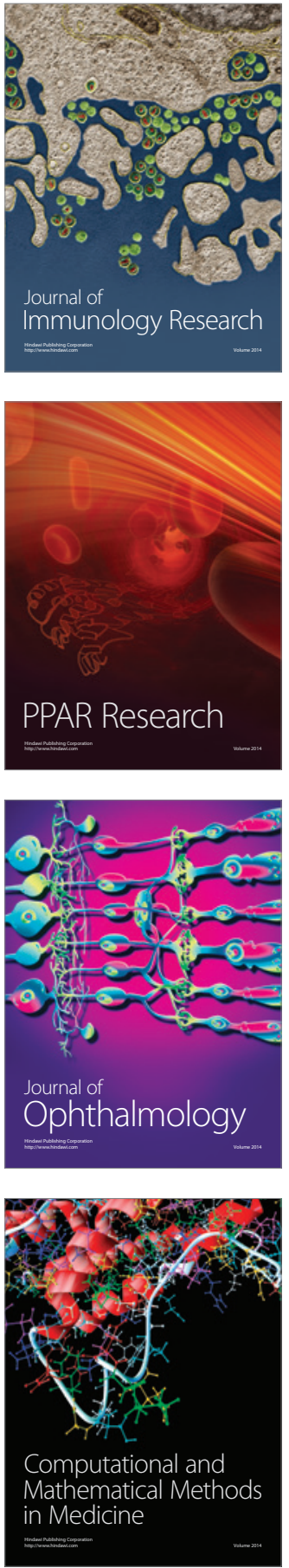

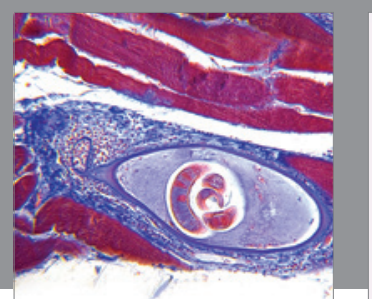

Gastroenterology Research and Practice

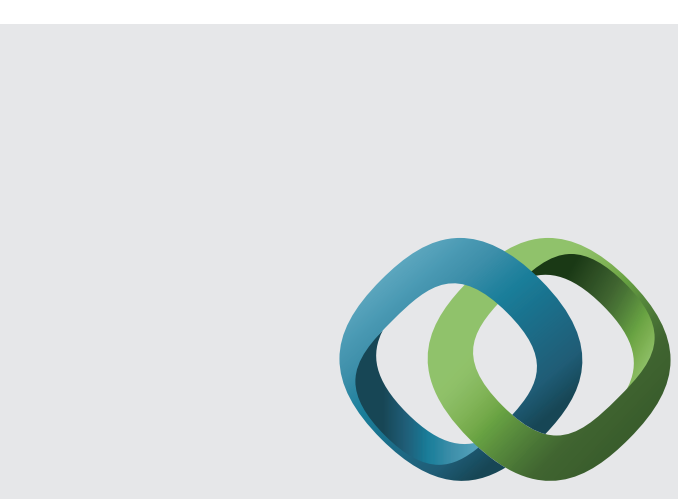

\section{Hindawi}

Submit your manuscripts at

http://www.hindawi.com
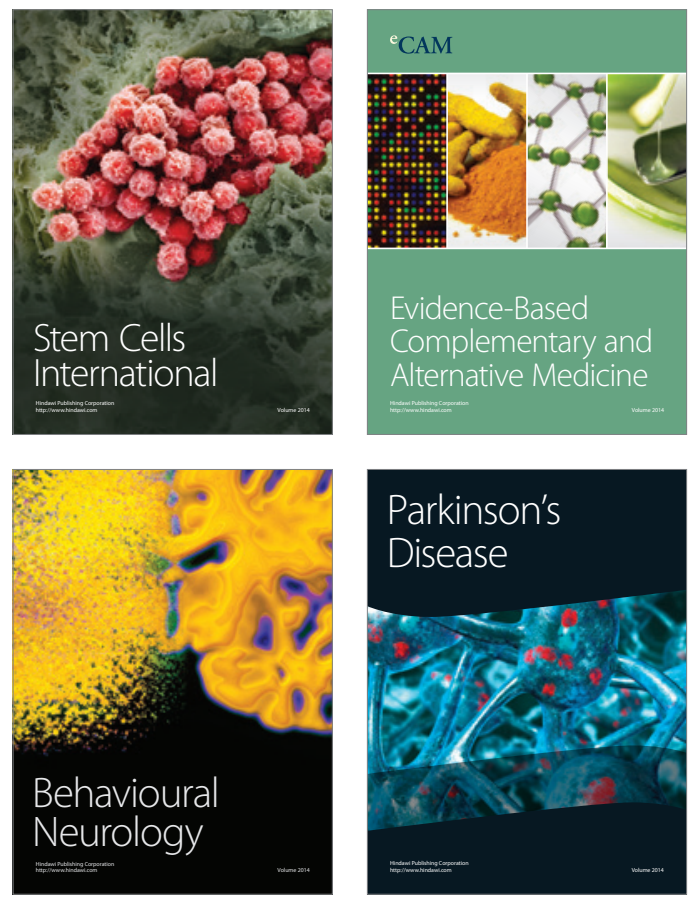
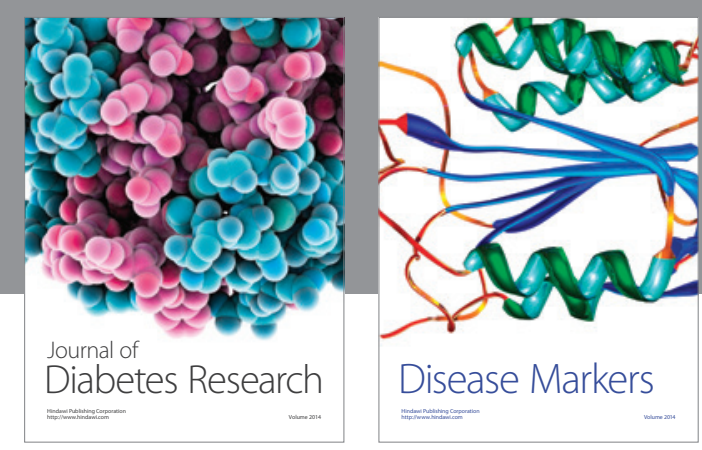

Disease Markers
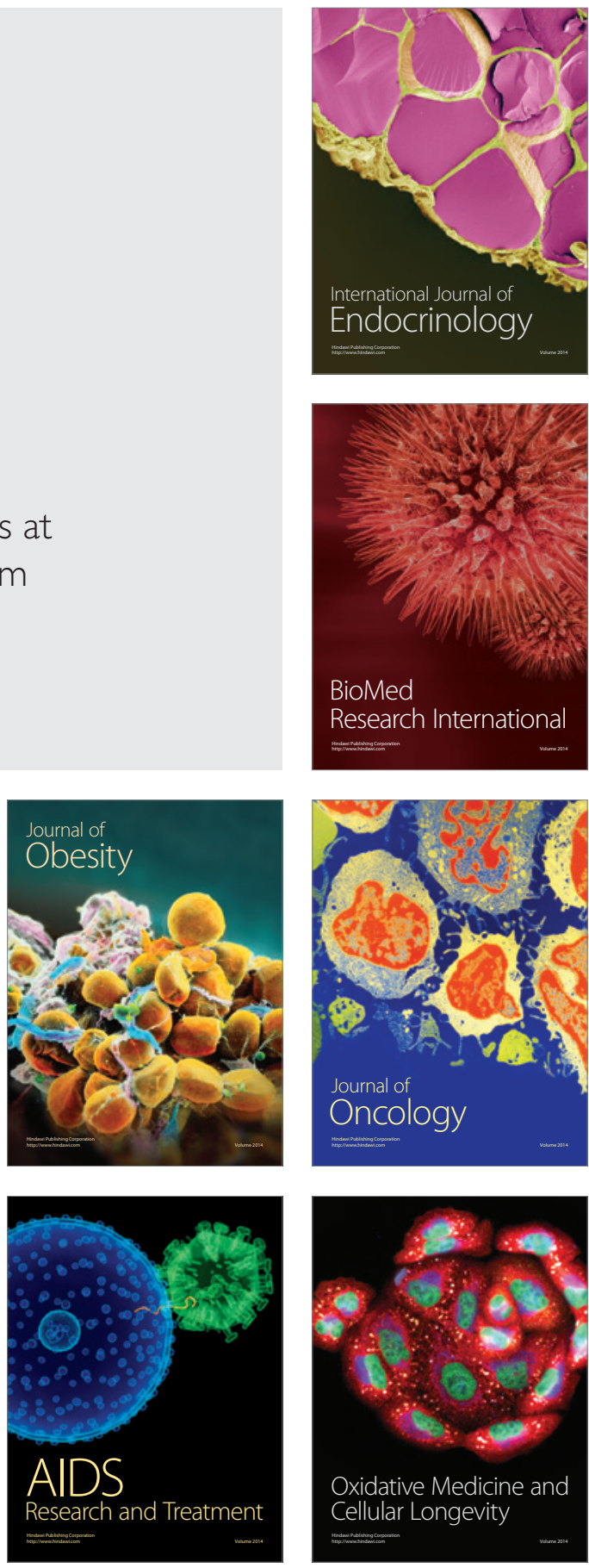